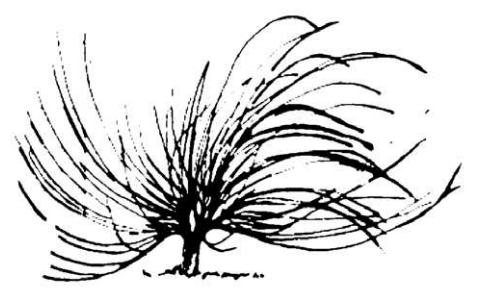

\title{
Arturo Andrés Roig, maestro de nuestra América. Una aproximación a su pensamiento pedagógico
}

\author{
Andrés Mora Ramirez ${ }^{1}$ \\ Universidad Nacional de Costa Rica \\ Heredia, Costa Rica \\ andres.mora.ramirez@una.cr
}

\section{Resumen}

En este ensayo se realiza una aproximación a la vida, la obra y al pensamiento pedagógico de Arturo Andrés Roig (1922-2012), filósofo y pedagogo argentino, precursor de la filosofía de la liberación en la llamada Escuela de Mendoza, con el propósito de divulgar sus ideas y aportes en nuestras latitudes geográficas y académicas: un pensamiento poco conocido y menos estudiado todavía en los centros dedicados a la formación y profesionalización docente en la Universidad Nacional de Costa Rica.

Palabras clave: pedagogía latinoamericana, filosofía de la educación, historia de América Latina

\begin{abstract}
The following essay examines the life, the work and the educational thought of Arturo Andrés Roig. Roig was a philosopher and a professor who guided the Philosophy of Liberation at the research institute of the "Escuela de Mendoza in Argentina." This essay aims to make known
\end{abstract}

Recibido: 10 de febrero de 2013 - Aprobado: 11 de octubre de 2013

1 Magíster en Estudios Latinoamericanos con énfasis en Cultura y Desarrollo. Investigador y docente de la Universidad Nacional, en el Instituto de Estudios Latinoamericanos de la Facultad de Filosofía y Letras, y en la División de Educología del Centro de Investigación y Docencia en Educación. 
Roig's ideas and contributions to our geographical latitudes and educational settings where his thought is little known and even less studied in the teacher education programs of the "Universidad Nacional" of Costa Rica.

Keywords: Latin American pedagogy, philosophy of education, Latin American history

\section{El riesgo y el terror}

U n viento fuerte azota nuestras ventanas y no lo vamos a impedir cerrándolas. Creo que nuestra universidad nos invita $-\mathrm{y}$ nuestros jóvenes nos están invitando- a jugar un papel de maestros, no de catedráticos de materias o asignaturas, sino de maestros de vida, con los riesgos que esto significa. Arturo Andrés Roig (1971)².

EXPULSADO: Mendoza, Argentina, 1 agosto de 1975. El Rector Interventor de la Universidad Nacional de Cuyo, visto el "pedido de limitación de las designaciones de personal docente efectivo, formulado por el señor Decano Interventor de la Facultad de Filosofía y Letras", resuelve limitar al día 31 de julio de 1975 la designación del profesor Arturo Andrés Roig en la cátedra de Historia de la Filosofía Antigua (Resolución No 1616, 1975).

“En el año de 1975 [Arturo Andrés Roig fue] expulsado de su cargo universitario en Mendoza. Sobre la Argentina se había abatido una ola represiva que asfixió cuanto se había avanzado de progreso y democracia. La muerte de [Juan Domingo] Perón trajo una crisis interna de su movimiento y la consiguiente derrota de lo más sano del mismo. El paramilitarismo entronizado por la Triple A, Alianza Anticomunista Argentina, abrió paso a un nuevo y brutal golpe militar en 1976. Cuando avanzó el militarismo -sucio, implacable, inhumano y sangriento- dejó sentir sobre él, que ya gozaba de fama internacional y era uno de los más conocidos maestros de Latinoamérica, y otros colegas, su cercanía

2 Las citas que se presentan al inicio de cada apartado de este ensayo -con excepción del apartado número dos- corresponden al libro de Arturo Andrés Roig titulado: La universidad hacia la democracia. Bases doctrinarias e históricas para la constitución de una pedagogía participativa (1998, Mendoza: EDIUNC). 
amenazadora"(Pérez Morales, 2012). - Testimonio del Dr. Carlos Pérez Morales, geógrafo e historiador, miembro del Comité Ejecutivo de la Asociación Puertorriqueña de Historiadores.

NO CONFIABLE PARA LA DOCENCIA: 1976. El rectorado interventor emite la "nómina de personal a los cuales [sic] se les prohíbe el reingreso a la Universidad Nacional de Cuyo por considerárselos no confiables para la docencia". Figuran en la lista, entre otros, los docentes: Ezequiel Ander Egg, de Ciencias Políticas y Sociales; Adriana Arpini, Bernardo Bazán, Enrique Dussel, Arturo Roig y Oward Ferrari, todos de Filosofía y Letras; y siguen los nombres de $\mathbf{2 1 9}$ profesores y profesoras más, de las distintas facultades y centros de investigación del campus de Mendoza (Resolución No 1677, 1976).

"En 1975 fue declarado cesante, como tantos otros reformadores mendocinos, incluido su padre, y obligado a exiliarse. En 1976, el rector de la última dictadura cívico-militar, Pedro Santos Martínez, directamente le prohibió, junto a otros colegas, ingresar al predio de la Universidad Nacional de Cuyo". - Testimonio del profesor Martín Omar Aveiro, investigador de la Dirección de Educación Superior de la Provincia de Mendoza.

$* * * * *$

A mediados de la década de 1970, un viento terrible de la historia, distinto de aquel viento que reclamaba una nueva reforma universitaria y que Arturo Andrés Roig había oteado en el horizonte de sus reflexiones en el año 1971, azotó como un huracán las ventanas de la nación argentina: el régimen del terror de Estado, una fuerza brutal como nunca había conocido el cono sur, lanzaba sin escrúpulos su sombra de represión y muerte sobre todo el país.

Forzado al exilio por la conjura de los poderes fácticos y la reacción conservadora; expulsado de su universidad y con las puertas cerradas para trabajar en cualquier otra institución educativa de la Argentina, Roig, el filósofo, pero ante todo lo demás, el educador que decidió correr el riesgo de ser maestro de vida, no volvería a su tierra natal sino al 
cabo de casi diez años, en 1984: cuando la dictadura militar, humillada por su derrota en la guerra de Malvinas; manchada por la sangre de los miles de desaparecidos, torturados y asesinados en la guerra sucia ;y asfixiada por la creciente e insostenible deuda externa, cedía poco a poco los cerrojos de su sistema de dominación para el tímido retorno de la democracia.

\section{El hombre, sus ideas y su memoria: razones de una búsqueda}

Entramos en la lista de expulsados y perseguidos, tuvimos que escondernos y luego huir del país. Nos esperaban colegas y amigos universitarios en Europa, en particular en Francia, y en países latinoamericanos. Optamos por no salir de nuestro continente.

Arturo Andrés Roig (citado en Pérez Morales, 2012).

Al maestro Roig, que nació en 1922, solo pudimos conocerlo, paradójicamente, hacia finales del año 2012, unos meses después de su muerte: en Mendoza, su ciudad natal, y en el campus de la Universidad de Cuyo -de la que fue profesor, investigador y Secretario Académico-, su memoria y su recuerdo se advertían como una presencia cercana. Allí también confirmamos la impronta de su legado intelectual, y hasta la animadversión hacia su labor docente y su trayectoria universitaria: un odio que sobrevive oculto en las catacumbas del rencor y el oscurantismo ideológico3.

En los testimonios orales y escritos de quienes le conocieron, y acaso movidos por la curiosidad del oficio periodístico, nos dejamos seducir por el atractivo de su figura en el concierto latinoamericano y por la evocación apasionada de su obra. Entonces, fueron inevitables las preguntas: ¿Quién era ese hombre que sufrió todo el peso de la represión política e ideológica sobre su vida y su trabajo académico? ¿Cómo entender al educador proscrito por la maquinaria del terrorismo de Estado? ¿Por qué, dado su prestigio y reconocimiento internacional,

3 Sobre este punto, y las polémicas que todavía tienen lugar en el ámbito académico universitario de Argentina, recomendamos la lectura de: "No habrá más penas ni olvidos: el caso de la Facultad de Filosofía y Letras", artículo del profesor Martín Omar Aveiro, publicado el 22 de enero de 2012 en el diario Mendoza Opina y disponible en esta dirección: http://www.mendozaopina.com/politica/101-1/24952-no-habra-mas-penas-ni-olvidos-el-caso-de-filosofia-y-letras 
que le hubiera abierto con facilidad las puertas de los mejores centros académicos de Europa, decidió sobrellevar el exilio en nuestra América, en universidades de México y Ecuador?

Este ensayo representa nuestra contribución a la búsqueda de respuestas a tales cuestionamientos, derivados -como no podía ser de otra manera- de la inquietud personal de un docente universitario en formación, así como de la lectura del libro Bases doctrinarias e históricas para la constitución de una pedagogía participativa (1998), en el que Roig compiló sus principales escritos sobre educación y pedagogía. Complementamos esas reflexiones con el contrapunteo con otros textos de referencia de autores latinoamericanos, para dimensionar y ampliar nuestro ámbito de comprensión, y contextualizar así las influencias y el desarrollo de las ideas del intelectual mendocino.

Una pregunta básica orienta esta indagación: ¿qué hacía de Roig y sus ideas un elemento peligroso para el orden de terror y represión que imponía la dictadura militar a la sociedad argentina; y qué tienen que decir esas sus ideas, hoy, en el siglo XXI, a quienes tomamos la decisión de formarnos como docentes universitarios, lo que en cierto sentido es también una opción de vida? Sobre esto volveremos al final del ensayo, pero creemos que en la selección de temáticas y proposiciones de Roig que aquí presentamos, y que nos ayudan a construir un relato, un discurso cultural, el lector podrá identificar con claridad nuestro posicionamiento.

Asimismo, en un esfuerzo mayor por aproximarnos a la perspectiva pedagógica latinoamericana y caribeña, y a la necesidad de que los docentes universitarios se nutran en su preparación, y luego en su práctica, de los aportes nuestroamericanos, con miras a construir comunidades y relaciones educativas situadas ${ }^{4}$, este escrito también tiene como propósito divulgar el pensamiento de Roig en nuestras latitudes geográficas y académicas: un pensamiento poco conocido y menos estudiado en los centros dedicados a la formación y profesionalización docente en la Universidad Nacional de Costa Rica.

4 Asumimos aquí la perspectiva de Pinto Contreras (2012: p. 135), para quien el ser educador situado en América Latina supone "conocer y dominar los saberes profesionales que le permitan actuar como formador integral de los educandos con los cuales le toca interactuar"; y además, que interioriza los fundamentos y las prácticas de una identidad docente que "problematiza la opción unidimensional y sistémica [de la educación] que se reproduce oficialmente en las instituciones y organizaciones educacionales" (Pinto Contreras, 2012: p. 18) de nuestra región. 


\section{Recuperar la educación para el hombre, al hombre para el país y al país para nuestra América: los ejes del pensamiento filosófico/ pedagógico de Arturo Andrés Roig}

La universidad no es una isla dentro del país, como el
país no es una isla dentro del mundo. El saber ha de ser
universal, pero al servicio de lo nacional. La 'ciencia
pura' es un mito, como lo es también el 'saber objeti-
vo', cuando estos términos encubren un desentenderse
de los problemas sociales concretos. (...) Recuperar
la universidad para ponerla al servicio del hombre del
país, en el sentido pleno, supone recuperar el país y
recuperar ese hombre.

Arturo Andrés Roig

Antes de presentar los aportes del pensamiento de Arturo Andrés Roig en lo que se refiere a la pedagogía y a la andragogía, nos interesa perfilar, aunque sea de forma muy general -puesto que profundizar al respecto escapa a los propósitos y alcances de este ensayo-, los contornos de su pensamiento filosófico como un todo.

Son varios los grandes ejes que configuran el rumbo o la ruta crítica de la evolución de las ideas del maestro argentino, entre los cuales es posible identificar la emancipación y la democracia, el sujeto y su sentido histórico como constructor del mundo, la liberación como oposición a la dependencia, y lo nacional vinculado a una profunda vocación latinoamericanista. No obstante, consideramos que es este último eje, el del latinoamericanismo, el que articula buena parte de sus desarrollos teóricos, literarios y, evidentemente, pedagógicos. Tanto así que al emprender el exilio, en el que quizás fue el momento más dramático de su vida, toda vez que pendía sobre su destino y el de su familia el afán inquisidor de la dictadura, Roig decide seguir su camino intelectual y docente en nuestra América y no en Europa.

Al parecer, desde su juventud, cuando realizó su primer viaje al viejo continente en 1950, Roig había descubierto que su quehacer filosófico estaría signado por la problemática latinoamericana: comprendió "la necesidad de pensar o de ejercer el pensamiento con todas las técnicas que existen, con todas las exigencias técnicas del pensar académico pero aplicada a otra realidad y vista desde otra realidad" (Roig, 2012 citado en Aveiro, 2012). Por supuesto, desde nuestra realidad. 
Por eso, en el marco del desarrollo de la historia de las ideas y del pensamiento latinoamericano, es posible ubicar a Roig en ese fértil y bullente período que el filósofo cubano Roberto Fernández Retamar (2006, p. 55) denomina de "la utopía y radicalización de nuestro pensamiento", y que se extiende de los años cincuenta a finales de los años setenta del siglo XX, lapso en el que encontramos aportes tan originales como la teoría de la dependencia, la teología de la liberación y la filosofía de la liberación, que precisamente nace de la Escuela de Mendoza de Enrique Dussel y el propio Roig. Por su parte, Mora Rodríguez (2006, pp. 393404) contextualiza a Roig y su pensamiento en la llamada filosofia de la identidad latinoamericana, junto a figuras como el mexicano Leopoldo Zea, el uruguayo Arturo Ardao y el peruano Francisco Miró Quesada.

Desde el punto de vista del pensamiento pedagógico, y de la educación superior como tal, el latinoamericanismo de Roig encontró expresión en dos dimensiones: una, en la recuperación de las ideas de la integración regional como destino posible y deseable, y dentro de este proceso, el ideal bolivariano de la construcción de una universidad continental; y la otra dimensión fue la revalorización del legado de la reforma universitaria de Córdoba (1918) y del sistema de seminarios “como corazón de la enseñanza universitaria"(Biagini, 1995, p. 100).

Retomaremos el papel del seminario como práctica pedagógica más adelante. Ahora, queremos detenernos en un pasaje de una conferencia dictada por Roig en el año 2002, titulada: Necesidad de una segunda independencia, y que ilustra esos grandes ejes de su filosofar.

En los albores del siglo XXI, en una Argentina destrozada económica y moralmente por el neoliberalismo de los tecnócratas y los profetas del fin de la historia, situación que con mayor o menor intensidad se había vivido también en toda América Latina -y que en muchos países ya estaba siendo revertida por el ascenso de revoluciones y gobiernos de signo nacional-popular-, Roig (2002, 37-38) describía así el estado de cosas, y las tareas pendientes, en nuestra región:

La democracia y, particularmente, los ideales de una democracia participativa de claro sentido social, dependen de la emancipación [mental] de la que estamos hablando, con el agravante de que además estamos al borde de perder lo poco que nos queda de independencia, por lo que la tarea, tal como lo vio [Manuel] 
Ugarte $^{5}$ en su momento, muestra dos frentes y de alguna manera hemos regresado al punto desde el que partió Francisco [de] Miranda $^{6}$ : un mundo colonial y una mentalidad colonial.

Ante este desolador panorama, el filósofo mendocino veía en la educación (por la vía de la emancipación mental) el elemento que unía su ideario de independencia y liberación del ser humano y de los pueblos. Permítasenos citarlo en extenso para fundamentar con la evidencia nuestra apreciación:

Frente a esta situación de dependencia acompañada de impunidad y corrupción, la tarea es doble: se hace urgente abrir una frente lucha por el rescate de la independencia perdida y poner en marcha una segunda independencia, así como es necesario y urgente promover una emancipación mental, no sólo ante los modos de pensar y obrar de las minorías comprometidas con el capital trasnacional y las políticas imperiales, enfrentados a los intereses de la nación, sino ante la contaminación ideológica generada por las prácticas de una cultura de mercado en las que se subordinan las necesidades (needs) a las satisfacciones (wants). Una vez más debemos hablar aquí de "contaminación" y definir la emancipación mental como lucha contra ella, hasta reducirla, de ser posible hasta una mínima burbuja. Así, pues, ya no se habla de un "pueblo ignorante" que ha de ser educado a efectos de que el país pudiera ingresar en el torrente del progreso, objeto en el que fijaron la emancipación mental las minorías del siglo XIX y buena parte del XX, sino de limpiarnos todos de aquella "contaminación" que en algunos ha alcanzado grados de inmoralidad profunda (Roig, 2002, pp. 38-39).

Es este un pensamiento maduro en sus enfoques críticos y en el señalamiento de las vías para la regeneración de las sociedades latinoamericanos, y no era para menos: la de Roig era una palabra fundada en la experiencia y que, al despuntar el nuevo milenio, podía alzar su voz con la autoridad moral de quien presenció el auge del capitalismo

5 Manuel Ugarte (1875-1951) fue uno de los principales intelectuales argentinos en la primera mitad del siglo XX, y se le puede ubicar como un latinoamericanista, antiimperialista e identificado con el socialismo nacional. Fundó la Revista Literaria en Buenos Aires y militó activamente en el movimiento universitario de la Reforma de Córdoba; de él, Gabriela Mistral dijo alguna vez que era "el Juan Bautista del hispanoamericanismo".

6 Francisco de Miranda (1750-1816) fue un político, militar y diplomático venezolano, considerado el ideólogo de las primeras etapas de las guerras de independencia de principios del siglo XIX, y para algunos, el padre de la emancipación hispanoamericana. 
neoliberal, ese al que los fusiles y los campos de concentración de las dictaduras militares le abrieron camino; era una voz que podía hablar con la entereza de quien sobrevivió al exilio sin renunciar a sus principios, y que ahora contemplaba el ocaso de toda una forma de mirar y organizar el mundo que influyó de un modo determinante en la historia del último cuarto del siglo XX latinoamericano.

\section{La pedagogía participativa universitaria: teoría y praxis desde nuestra América}

La universidad supone, en la medida en que es una comunidad educativa, un problema pedagógico; que posee por eso mismo una problemática que no se confunde con la de otras comunidades educativas y sobre la cual debe estructurarse un saber pedagógico sistemático.

Arturo Andrés Roig.

Hemos visto ya que las ideas de Roig, enraizadas en la realidad latinoamericana, también lograron proyectarse hacia otras esferas del quehacer humano -como la política, la historia, la cultura o la cuestión de nuestra identidad- en las que la filosofía era decisiva para configurar un pensar crítico y para impulsar las acciones consecuentes con ese pensamiento. Las ciencias de la educación, y en particular, la pedagogía universitaria, no fueron una excepción a ese carácter expansivo de su producción intelectual que abarcó tanto la teoría como la praxis.

En este sentido, Rochetti (2011, p. 18) afirma que uno de los principales aportes del pensamiento de Roig en lo pedagógico "radica fundamentalmente en el ejercicio de su trabajo de educador y en la reflexión de su propia práctica docente". Además, destaca el hecho de que logró teorizar desde ese lugar epistemológico - el del docente que reflexiona críticamente sobre sí mismo-, y luego, desarrollar en las aulas un nuevo tipo de relaciones entre el educador y los educandos, basadas en el reconocimiento de la alteridad, a saber, del otro como sujeto activo de su formación en el proceso educativo, lo que rompe con la circularidad de las relaciones tradicionales donde "el educando es en este sentido pasivo, receptor de la forma o la idea del educador" (Rochetti, 2011, p. 23). 
Para esta misma autora, otro mérito del filósofo mendocino fue la inclusión, en los debates y discusiones teóricas sobre educación y pedagogía, de los conceptos o nociones de "la historicidad y la comunicación como lo propio de la relación pedagógica" (Rochetti, 2011, p. 26). Historicidad que debe entenderse como oposición a lo imitativo, a lo que ocurre naturalmente, sin posibilidad de transformación a partir de la conciencia del ser humano-del educando- de sus potencialidades y su necesidad de liberación.

Precisamente, de nuestra lectura de la obra de Roig, podemos complementar lo anterior diciendo que uno de los aspectos más llamativos, sobre todo por la fuerza con la que interpela al docente sobre las dimensiones y fundamentos de sus prácticas pedagógicas, es su llamado a construir relaciones educativas sustentadas en el marco de la filosofía de la alteridad y de la pedagogía liberadora: es decir, relaciones que rompan con los hábitos y patrones de dependencia (bajo la forma dominador/ dominado) en todos los niveles del sistema educativo y de la sociedad.

$\mathrm{Al}$ respecto, Roig era enfático al sostener que para que se constituya una auténtica pedagogía de la alteridad o de la liberación "es necesario dar un nuevo contenido y valor a los principios mismos de la pedagogía", lo que implica que, a la vez, se debe "repensar la 'libertad', el 'amor', la 'patria', el 'pueblo', etc. y rescatarlos, mostrando el grado y el modo en que dentro del contexto social, han perdido sus verdaderos contenidos, su verdadera universalidad" (Roig, 1998, p. 64).

Esa "nueva pedagogía" por la que trabajó Roig, se nutría de un marcado y profundo sentido social, en el entendido de que solo desde esa esfera de lo humano se generaría una actitud crítica que permitiría al educando convertirse en "factor primero y fundamental de su propio desarrollo", dentro y fuera de la escuela o el sistema educativo formal, y agregaba:

Es necesario que la injusticia, el hambre, la enfermedad, el dolor y la explotación existentes se constituyan, aun cuando ello suene a paradoja, en elementos educativos a favor de la constitución de un nuevo estado de conciencia. No se trata de crear conciencias 'caritativas', sino simplemente justicieras. Es necesario que los marginados de todos los órdenes, aquellos que con su presencia y su fuerza tienen el poder de quebrar los universales ideológicos y de exigir una nueva libertad, un nuevo Dios, una nueva nación, 
adquieran la capacidad de organizar socialmente su presencia y su fuerza. (Roig, 1998, p. 64-65)

En este punto, y dado que su trayectoria docente la realizó en la educación superior, cabe preguntarnos cómo concebía Roig la pedagogía en la universidad, o mejor aún, para usar sus términos, la pedagogía universitaria, dada la naturaleza crítica, diversa y situada en nuestra América de sus influencias filosóficas, que alentaban en sus planteamientos una suerte de ruptura epistémica y a una renovación de todo lo conocido y establecido. Pues bien, en su perspectiva:

La pedagogía universitaria podría ser definida diciendo que es la conducción del acto creador, respecto de un determinado campo objetivo, realizado con espíritu crítico entre dos o más estudiosos, con diferente grado de experiencia respecto de la posesión de aquel campo. El ejemplo más acabado de esta pedagogía del acto creador posiblemente sea el diálogo socrático, por donde toda pedagogía universitaria tal vez no consista en otra cosa que volver a él según las circunstancias y los tiempos. (Roig, 1998, p. 19)

Consecuente con lo anterior, en una conferencia dictada en la Universidad de Cuyo, en 1967, Roig sostenía que, confinada "a las primeras edades del educando", y sometida a mil y un prejuicios "por muchos académicos satisfechos con la posesión de su saber científico", o vista por otros como "un saber meramente técnico incompatible con el humanismo", durante mucho tiempo la pedagogía en las universidades latinoamericanas se mantuvo reducida "a un simple saber empírico" (1998, p. 17).

En esa ocasión, Roig desatacó la función del seminario como modalidad y estrategia de enseñanza y aprendizaje, toda vez que permitía "la realización plena de los fines de toda pedagogía universitaria", a cuya naturaleza deberían estar condicionadas "todas las demás estructuras educativas: clases, programas, exámenes" (Roig, 1998, pp. 24-25). Para nuestro autor, el seminario y el laboratorio constituían "las formas de relación pedagógica más efectivas", porque profundizan "la relación entre el educador y el educando" (Roig, 1998, p. 19), que cuando se da de modo perfecto, "supone la coparticipación en la tarea de creación de aquel mundo de objetividad cultural" creciente entre ambos y entre su específico campo de saber. 
Según Rochetti, esta nueva manera de entender la pedagogía, con un fuerte ascendiente de la idea de participación, llevó a Roig a plantear:

Una integración docente-alumno, en la cual el alumno sea el propio protagonista de su desarrollo. Esto implica una crítica a la actitud paternalista del docente que asienta su práctica en la idea de su ser paradigmático y de algún modo referencial que pretende consumarse en la imitación como modo de relación. [...] Esta pedagogía no implica una ruptura con la relación maestro-alumno, sino una reubicación, un nuevo posicionamiento de ambos. (Rochetti, 2011, p. 24)

De esta amplia noción de pedagogía participativa universitaria que construyó Roig, y que comentan y puntualizan otros autores, es posible deducir, en nuestro criterio, un elemento crucial para la docencia universitaria contemporánea: nos referimos al carácter dialógico -y dialéctico- de una relación educativa que tiene lugar entre sujetos que, al reconocer la alteridad implícita en su puesta en común, se encuentran en condiciones de llevar adelante, siempre que exista mutuo convencimiento (es decir, si participan desde su propia voluntad y su conciencia), un acto transformador por excelencia como es el hecho educativo.

Hasta aquí hemos expuesto las contribuciones de Roig derivadas de sus formulaciones teóricas. Demos paso ahora al estudio del legado de su praxis pedagógica.

Siguiendo al investigador argentino Hugo Biagini, debemos indicar que los aportes del maestro mendocino a lo que llamamos la perspectiva pedagógica latinoamericana y caribeña, pueden identificarse en el orden de lo teórico - como ya lo comprobamos- y de lo experiencial. Entre los primeros, se encontrarían su crítica "a la enseñanza magistral y su defensa de la actitud dialógica y problematizadora, de la participación creativa del alumno universitario", "su reflexión sobre las ligazones entre Universidad y región para superar la antinomia entre localismo y universalismo, entre una universidad pragmático-profesional y una universidad científico-investigativa", y "su rechazo a los universales ideológicos empleados por una pedagogía opresora que niega la personalidad del educando". Y entre los aportes experienciales, destacarían dos: por un lado, "la intervención directa del propio Roig en el ensayo de pedagogía universitaria participativa llevado a cabo en 
Mendoza durante el período que va de 1973 a1974", caracterizada por el rechazo de los supuestos de las teorías desarrollistas que pretendían someter a la universidad al dictado de la racionalidad tecno-económica; y por el otro, su opción por la liberación, reflejada en la elaboración de las bases estatutarias de un nuevo modelo académico-pedagógico "siempre vigente porque implica pelear, como aduce su enunciador, contra la alienación [y] por el crecimiento espiritual y material del hombre" (Biagini, 1995, pp. 100-101).

¿En qué consistió esa experiencia de pedagogía participativa aplicada en la Universidad de Cuyo a mediados de la década de 1970, en aquellos años por demás convulsos, precedidos de las movilizaciones estudiantiles de París y México en 1968; del crecimiento demográfico y su presión sobre la matrícula juvenil universitaria en América Latina; y del fin de los años dorados del desarrollismo y del modelo económico de sustitución de exportaciones?

En sus escritos, Roig aborda ampliamente los sucesos de dicho período, tanto en sus fundamentos filosóficos, pedagógicos y legales, como en la reconstrucción del proceso administrativo que permitió poner en práctica el modelo académico de pedagogía participativa. Por razones obvias, no nos detendremos en un recuento minucioso de estos aspectos, y bastará por ahora referir al lector a dos de sus textos imprescindibles: el artículo "Un proceso de cambio en la universidad argentina actual (1966-1973)", publicado en la Revista de Filosofia Latinoamericana de Buenos Aires en 1975; y la conferencia "Un experimento de pedagogía universitaria participativa. El ensayo de los años 1973-74", leída en la Universidad Nacional de San Luis, en Argentina, en 1985.

Para los propósitos de nuestro ensayo, y por considerarla mucho más ilustrativa, vamos a reseñar algunos pasajes de una entrevista que realizó la Radio Universidad Nacional de Cuyo a Arturo Andrés Roig, en junio de 1989. En aquel encuentro, Roig explicó que los antecedentes y fundamentos pedagógicos del modelo de pedagogía participativa se encuentran en "la Escuela Activa proyectada en la Universidad" (Roig, 1998, p. 283), en los ensayos que ya había realizado el Dr. Julio Herrera en la Facultad de Ciencias de la Educación de la Universidad de San Luis y, como influencia latinoamericana inequívoca de la época, en las ideas de Paulo Freire.

Este modelo, decía Roig, "era bastante participativo y se apoyaba en la convicción de la capacidad creadora del alumno", toda vez que los 
estudiantes se involucraban directamente en las tareas de gobierno universitario, en la construcción y gestión del currículum, y en la organización y desarrollo del proceso de enseñanza/aprendizaje, desde el doble lugar de educandos y de tutores/investigadores. Para esto, se puso en marcha un sistema de departamentalización interna de las facultades y escuelas universitarias que implicaba, "desde el punto de vista estructural, la eliminación del antiguo sistema de cátedras y su reemplazo por 'unidades pedagógicas' o 'áreas', las que estaban destinadas a favorecer una extrema movilidad interna, sobre todo de los docentes, sin que el sistema les hiciera perder, por cierto, su estabilidad" (Roig, 1998, p. 283).

Las unidades pedagógicas, conformadas por profesores y estudiantes, tal y como se las concebía, aspiraban a ser "ensayos de desescolarización" que debían convertirse, progresivamente, en estructuras "abiertas y con un potencial interior capaz de ir rompiendo las sucesivas e inevitables formalizaciones en las que cae, por el peso de una tradición educativa opresora, todo intento de transformación de las relaciones educativas" (Roig, 1998, p. 124).

Este modelo de pedagogía participativa se sintetizaba en tres objetivos: "docencia, investigación y servicio" a la comunidad, "llevados a cabo como parte de los estudios y, en algunos casos, de la investigación". Como decía Roig (1998, p. 284), "pensábamos que las profesiones no son medios para enriquecerse sino que son antes que nada servicios".

Una vez más, por su valor testimonial, y por lo que expresa en términos de hacer visibles las influencias filosóficas, pedagógicas y políticas -en la correcta acepción de la palabra- del Secretario Académico que abanderó este intento de cambio en la Universidad de Mendoza, vamos a tomar una nueva licencia y a transcribir dos párrafos de la entrevista en cuestión:

Se trataba de una nueva orientación en los estudios y, si se quiere, de implementar una nueva misión de la Universidad Argentina. Se pretendía hacer una Universidad que partiera de la misma sociedad civil, con un claro sentido nacional y latinoamericano. Mas, también, fuertemente crítica tanto de sí misma como de la realidad extra-académica. En esto de la criticidad, por cierto que el despertar estudiantil significó un aporte inestimable. [...] Queríamos, además, hacer una Universidad pluralista y en cuanto a nuestros ideales latinoamericanos, nuestra posición podía 
entenderse como un regreso a Manuel Ugarte y José Ingenieros. Por cierto que está de más recordar que una de las problemáticas centrales de aquellos años, que no han perdido actualidad, giraban sobre la cuestión de la liberación versus dependencia. (Roig, 1998, pp. 284-285)

Desgraciadamente, resulta imposible saber qué hubiese ocurrido con esta singular experiencia si la crisis política, la intolerancia, los extravíos del sentido común y el estado de excepción impuesto por la dictadura militar argentina, no se hubieran interpuesto en el proyecto de Roig y sus colegas. Tampoco podemos hacer una valoración de los resultados pedagógicos concretos de dicho proceso de reforma. Sabemos que algunos docentes mendocinos en el exilio, como Roig y Ezequiel Ander Egg, pusieron en práctica versiones de este modelo en la Universidad Central de Ecuador y en la Escuela de Trabajo Social de la Universidad de Barcelona, respectivamente.

\section{El andar que hace al camino: la andragogía y su método en el pen- samiento roigeano}

¿Cómo podremos dialogar con el alfarero, con el barrendero, con el peón de campo, con la mujer de los barrios pobres, con el presidiario, si los miramos como incapaces, como ignorantes, como casi-seres humanos? ¿Cómo ayudarlos a rescatarse a sí mismos en ese reencuentro del hombre consigo que es el descubrirse como transformador del mundo?

Arturo Andrés Roig

Una última escala en este recorrido de aproximación al pensamiento filosófico y pedagógico de Roig, nos lleva a considerar sus reflexiones en torno a la educación y la alfabetización de adultos, en el contexto mayor de los problemas y desafíos socioeconómicos de la Argentina y de América Latina en los últimos 35 a 40 años.

Si bien existe un debate teórico entre pedagogía y andragogía, y se las separa en el entendido de que su objeto de estudio -y de acciónes distinto (Aguilar Fernández, 1994), conviene aclarar que en las ideas del filósofo y pedagogo argentino, esa diferencia se diluye en el análisis 
global del problema de la mediación en el proceso de aprendizaje. Roig incursionó en el filosofar sobre la pedagogía juvenil y universitaria, pero no disoció ese ejercicio de la búsqueda de respuestas para enfrentar el problema de la enseñanza de y con los adultos. Valga decir, la cuestión andragógica como tal.

Así, en 1971, en una conferencia en la Casa del Maestro de Mendoza, ya encontramos un interés intelectual importante en esa dirección, cuando afirmaba que la discusión sobre la alfabetización universal en nuestro continente debía llevarnos, inevitablemente, a "tratar el problema de la inserción del método en la vida, en relación con el tema de la 'alfabetización de adultos', visto en sí mismo como problema pedagógico en su más amplio sentido y además, en una de sus últimas y más notables manifestaciones" (Roig, 1998, p. 41).

Su preocupación principal, en este ámbito, giraba alrededor de la inserción del método andragógico en la vida del educando, como oposición a los modelos de la tradición educativa opresora: para que un método sea realmente efectivo, creía Roig, debía“ estar inserto en la vida. Afirmación esta que supone que hay métodos que se escinden de la vida, que no son función de la vida y que pretenden sin embargo constituirse en normas de vida aun cuando sea fuera de la vida misma". De estos últimos, nuestro autor pensaba "que constituyen métodos o caminos que sólo pueden llevar a fracasos pedagógicos. (...) Son ellos [dicho métodos] sin más verdaderos obstáculos para la humanización $\mathrm{y}$ en tal sentido la puerta para la organización de sociedades humanas injustas" (Roig, 1998, pp. 42-43).

Valiéndose del conocido verso del poeta español Antonio Machado (caminante no hay camino / se hace camino al andar), Roig identificó dos momentos del acto educativo: uno, el que corresponde a la selección del método -el camino-; y otro, el que es propio de la enseñanza -el andar-. Y puntualizó: "mas de los dos, el principal, el que da sentido al acto educativo, no es el camino, sino el andar que hace al camino". Pero en esta visión, también incluyó un matiz: en la distinción "al parecer tan inocente entre el camino y el andar, se esconde pues una división de tendencias ante las cuales el pedagogo deberá optar y en esa opción le irá en juego nada menos que su misma condición de pedagogo, que nunca puede ser ni más ni menos que la misión de ser hombre" (Roig, 1998, 43). 
En efecto, para él no era aventurado afirmar que en la tarea de la alfabetización y la enseñanza de adultos también estaba en juego la posibilidad de humanizar o deshumanizar. En este punto, Roig se acercó a los hallazgos y postulados de su colega Paulo Freire. Para el maestro mendocino, por ejemplo, el adulto analfabeto es "por lo general un ser oprimido, aplastado y temeroso. Es un hombre humilde y de baja condición social y económica. Es un hombre al que muchas veces se le niega condición humana y al que siempre se le negaron los derechos políticos" (Roig, 1998: 44).Y en un sentido muy similar, el pedagogo brasileño fundaba su pedagogía de la liberación en el reconocimiento, por parte de los educandos, de su condición de oprimidos: aquí la libertad, y la educación como práctica de esa libertad, solo podía ser alcanzada en la medida que esos hombres y mujeres, analfabetos, negados en su condición humana, descubren que alojan al opresor en sí mismos, que son portadores y reproductores de la dominación (Freire, 2002, p. 35).

Como ya hemos dicho, Roig no se refiere propiamente a la andragogía bajo ese concepto, pero sí postuló algunas características de lo que entendía como el método pedagógico para el trabajo con adultos: el suyo era un enfoque que superaba la "mera técnica psicológica y de adiestramiento", para fundarse en "un método que no quiere y no puede dejar de ser sociológico y humanizador. Un método que ve en el hombre un ser social y que parte además del presupuesto de que solo en la sociedad puede el hombre alcanzar su humanización" (Roig, 1998, p. 45).

En cuanto al desarrollo del método andragógicoroigeano, encontramos correspondencia con los principios que, durante la segunda mitad del siglo XX, se fueron sistematizando poco a poco hasta constituir el corpus de la andragogía: el autoconcepto del educando, la motivación, la participación, la horizontalidad y el aprendizaje basado en la experiencia, por citar algunos (Aguilar Fernández, 1994). Roig sostenía que frente a ese adulto que "ha perdido el sentido originario de su relación con su mundo", la misión del docente consiste en "hacerle vivir a ese hombre, con procedimientos sencillos y eficaces, que él también en cuanto ser humano es 'constructor' de su mundo. Habrá que hacerle ver cómo él, porque es hombre, también con sus manos 'transforma' el mundo" (Roig, 1998, p. 46).

En su método andragógico aparecen dos herramientas fundamentales: una es el diálogo como actitud que define la relación educativa y la provee de contenido emancipatorio; y la otra, el enfrentamiento 
del educando "con sus propias situaciones existenciales", es decir, con sus experiencias de la vida, las cuales, sometidas a análisis, provocarán "un proceso de autoposesión y de concientización del hombre en cuanto hombre" (Roig, 1998, p. 52).

Una idea final sobre esta temática nos muestra a Roig en toda su dimensión de maestro de vida, y como en otros de sus planteamientos, encontramos también una convergencia con los desarrollos teóricos y empíricos de Paulo Freire en sus trabajos sobre educación y alfabetización de adultos, y que tuvieron un impacto decisivo en la formulación de la pedagogía de la liberación. Decía el intelectual mendocino: "De nada servirá sin duda enseñarles sin más una técnica de lectura [a los adultos], que podría incluso venir a reforzar su estado de enajenación. La alfabetización es y debe ser concientización de nuestro hombre oprimido y fatalista" (Roig, 1998, p. 49).

\section{Vivir más allá de la vida: lecciones y aprendizajes a partir de la lectura de Roig}

Hemos vivido momentos en que creíamos que la historia realmente nos estaba pasando por encima. Sin embargo, no hemos perdido ese optimismo, es un optimismo diría yo recalcitrante, un optimismo a pesar de todo, que se apoya a lo mejor en las cosas muy simples, en el hecho de que seguimos viviendo, de que podemos seguir luchando, de que se puede seguir diciendo las cosas que se piensan, ya sea acá o en otro lugar del mundo.

Arturo Andrés Roig, 1993.

En las primeras páginas de este ensayo, dejamos constancia de una pregunta que recorría, con inusual urgencia, el afán de sistematizar los hallazgos de nuestra lectura de los escritos de Arturo Andrés Roig y su relación con el tiempo histórico que le correspondió vivir. Era una preguntaba sobre lo que sus ideas todavía tienen que decir, en esta nueva centuria, a los docentes universitarios en formación, y sobre lo que podemos aprender para nuestra práctica docente y el enriquecimiento de nuestros saberes pedagógicos.

Al concluir nuestro peregrinaje a la obra de Roig, podemos afirmar que su pensamiento, que aquí hemos intentado esbozar, conserva 
plenamente su vigencia y, más aún, nos invita a redescubrirlo, explorarlo e incorporarlo como un referente en la formación de docentes situados en la realidad social y educativa latinoamericana. Desde esa perspectiva, la lección de Roig es contundente: no hay pedagogía ni docencia, entendidas como prácticas intelectuales y culturales, que puedan estar desligadas de las problemáticas profundas de nuestros contextos sociales, políticos, económicos y culturales; ni es posible encarar los desafíos de la educación - cuando esto se hace con autenticidad- sin un firme compromiso ético y de transformación y liberación de la persona humana y de la sociedad en su conjunto. Ética y pedagogía, pues, se nos revelan como un binomio inseparable.

Asimismo, si aceptamosque uno de los grandes desafíos filosóficos y epistemológicos de nuestraépoca es aprender a ser docentes situados en América Latina, entonces, ese legado intelectual, ético y pedagógico de Roig, y de tantos otros pensadores, maestros y maestras ilustres de nuestra región, constituye una fuente indispensable de conocimientos originales y creativos que nos permiten comprender a cabalidad el rol del docente en la educación del presente y del futuro. En esa línea de argumentación, resultan claves las palabras de Pinto Contreras (2012, p. 15), quien sostiene que en América Latina necesitamos:

legitimar una mirada sobre estos principios [filosóficos y epistemológicos], que fundamentan la práctica formativa, pero, esta $v e z$, desde la historia, las identidades socio-culturales, las tradiciones ético-políticas y pedagógicas que nos constituyen como territorios latinoamericanos. Solo desde ese rescate de lo propio podríamos entender las condiciones teóricas y políticas que nos impiden avanzar en el desarrollo de una educación propia, que dé más calidad a los procesos y productos formativos que desarrollamos con nuestras prácticas formativas.

¿Cómo avanzar en ese rescate de lo propio, sustento de todo proceso de construcción de nuevas realidades en nuestros países, y cómo hacerlo desde el campo de la educación y la docencia? Una tarea prioritaria para dar pasos en la dirección sugerida por Pinto Contreras (2012), y que también está presente en la obra de Roig, consiste en recuperar las tradiciones y fuentes filosóficas y pedagógicas latinoamericanas. Es decir, se trata de abocarnos individual y colectivamente a la tarea de 
rastrear, identificar y apropiarnos una vez más de las principales ideas y propuestas pedagógicas que han estado vinculadas al desarrollo social y cultural de nuestros pueblos, especialmente en su dimensión liberadora.

Finalmente, sabemos que la historia no trabaja con supuestos ni con expectativas sobre aquello que pudo ser y no fue; sin embargo, es nuestra convicción, a partir del estudio de los materiales a los cuales hemos tenido acceso, que Roig y sus contemporáneos, en las difíciles condiciones que tuvieron que enfrentar, avanzaron por un camino al que hoy tendría que volver la Universidad latinoamericana: el de la búsqueda de sus raíces culturales, de sus propias respuestas pedagógicas y de una vinculación real y profunda con el compromiso de transformar las sociedades para hacerlas más justas y democráticas.

Retomar esa ruta, con los riesgos implícitos en ella, pero también con el germen de sus inmensas promesas, es un reto para los docentes de nuestra América en el siglo XXI. Acaso asumir esa opción, en la multiplicidad de sus consecuencias y en la profundidad de sus responsabilidades, como lo hizo Roig, ya signifique empezar a vivir aquí más allá de la vida.

\section{Referencias bibliográficas}

Aguilar Fernández, V. (1994). Andragogía versus pedagogía. Un punto de vista comparativo. Educación y Ciencia. Educación y Ciencia, 3, (10), 11-16.

Biagini, H. (1995). El pensamiento universitario de Arturo Roig. CUYO. Anuario de Filosofia Argentina y Americana, 12, 99-103.

Fernández Retamar, R. (2006). Pensamiento de nuestra América: Autorreflexiones y propuestas. Buenos Aires: CLACSO.

Freire, P. (2002). Pedagogía del oprimido. -54 edición-. México, D.F: Siglo XXI Editores.

Mora Rodríguez, A. (2006). La filosofía latinoamericana: Introducción histórica. San José, C.R: EUNED.

Pinto Contreras, R. (2012). Principios filosóficos y epistemológicos del ser docente. San José, C.R: CECC/SICA.

Rochetti, C. (2011). El sentido de lo pedagógico en los textos de Arturo Roig. Revista Sul-Americana de Filosofia e Educação, 16, 17-29.

Roig, A.A. (1998). La universidad hacia la democracia: Bases doctrinarias e históricas para la constitución de una pedagogía participativa. Mendoza: EDIUNC.

Roig, A.A. (2002). Necesidad de una segunda independencia. Millcayac, Anuario de Ciencias Políticas y Sociales, 1 (1), 1-42. 


\section{Referencias de Internet}

Aveiro, M. (2012, 5 de mayo). "Un gran y sencillo hombre: Arturo Andrés Roig (19222012)", Revista Con Nuestra América. Consultado el 26 de enero de 2012, en: http://connuestraamerica.blogspot.com/2012/05/un-gran-y-sencillo-hombre-arturo-andres.html

Pérez Morales, S. (2012). "Adiós admirado y querido maestro. Semblanza de Arturo Andrés Roig". Boletín electrónico de ADHILAC. Consultado el 19 de enero de 2013, en: http://adhilac.com.ar/?p=7279

\section{Documentos digitalizados}

Resolución $\mathrm{N}^{\mathrm{o}}$ 1616. Rectorado Interventor de la Universidad Nacional de Cuyo. (Pedido de limitación de designaciones de personal docente efectivo). 1 de agosto de 1975. Centro de Documentación Histórica de la Universidad Nacional de Cuyo.

Resolución $\mathrm{N}^{\mathrm{o}}$ 1677. Rectorado Interventor de la Universidad Nacional de Cuyo. (Nómina de personal a los cuales se les prohíbe el reingreso a la Universidad Nacional de Cuyo por considerárselos no confiables para la docencia). 1976. Centro de Documentación Histórica de la Universidad Nacional de Cuyo. 